\title{
Stabilisation of amorphous furosemide increases the oral drug bioavailability in rats
}

\author{
Nielsen, Line Hagner; Rades, Thomas; Müllertz, Anette
}

Published in:

International Journal of Pharmaceutics

Link to article, DOI:

10.1016/j.ijpharm.2015.05.063

Publication date:

2015

Document Version

Peer reviewed version

Link back to DTU Orbit

Citation (APA):

Nielsen, L. H., Rades, T., \& Müllertz, A. (2015). Stabilisation of amorphous furosemide increases the oral drug bioavailability in rats. International Journal of Pharmaceutics, 490(1-2), 334-340.

https://doi.org/10.1016/j.ijpharm.2015.05.063

\section{General rights}

Copyright and moral rights for the publications made accessible in the public portal are retained by the authors and/or other copyright owners and it is a condition of accessing publications that users recognise and abide by the legal requirements associated with these rights.

- Users may download and print one copy of any publication from the public portal for the purpose of private study or research.

- You may not further distribute the material or use it for any profit-making activity or commercial gain

- You may freely distribute the URL identifying the publication in the public portal

If you believe that this document breaches copyright please contact us providing details, and we will remove access to the work immediately and investigate your claim 


\section{Stabilisation of amorphous furosemide increases the oral drug bioavailability in rats}

Line Hagner Nielsen ${ }^{1}$, Thomas Rades ${ }^{2, A}$, Anette Müllertz ${ }^{2,3}$

${ }^{1}$ Department of Micro- and Nanotechnology, Technical University of Denmark, Ørsteds Plads 345B, 2800 Kongens Lyngby, Denmark

${ }^{2}$ Department of Pharmacy, Faculty of Health and Medical Sciences, University of Copenhagen, Universitetsparken 2, Copenhagen, Denmark

${ }^{3}$ Bioneer:FARMA, Department of Pharmacy, Faculty of Health and Medical Sciences, University of Copenhagen, Universitetsparken 2, Copenhagen, Denmark

${ }^{A}$ Corresponding author: Department of Pharmacy, Faculty of Health and Medical Sciences, University of Copenhagen, Universitetsparken 2, 2100 Copenhagen, Denmark. Tel: +4535336032

Fax: +4535336001. E-mail address: thomas.rades@sund.ku.dk (T. Rades). 


\begin{abstract}
A glass solution of the amorphous sodium salt of furosemide (ASSF) and polyvinylpyrrolidone (PVP) (80:20 $\mathrm{w} / \mathrm{w} \%)$ was prepared by spray drying. It was investigated if PVP was able to stabilise ASSF during storage and dissolution and whether this influenced the in vivo performance of the glass solution after oral dosing to rats.

The glass solution had a glass transition temperature of $121.3 \pm 0.5^{\circ} \mathrm{C}$, which was significantly higher than that of the pure drug $\left(101.2^{\circ} \mathrm{C}\right)$. ASSF in the glass solution was stable for at least 168 days when stored at $20^{\circ} \mathrm{C}$ and $0 \%$ relative humidity. The glass solution exhibited fast dissolution in simulated intestinal medium, $\mathrm{pH}$ 6.5; the intrinsic dissolution rate was found to be $10.1 \pm 0.6 \mathrm{mg} / \mathrm{cm}^{2} / \mathrm{min}$, which was significantly faster than the pure ASSF. When investigating the stability during dissolution in stimulated intestinal medium at $\mathrm{pH}$ 6.5, the ASSF in the glass solution showed signs of crystallinity after 1 min of dissolution, but crystallised to a lesser extent than pure ASSF. The stabilising effect of PVP on ASSF, led to improved relative oral bioavailability in rats of $263 \%$, when compared to the pure ASSF.
\end{abstract}

Keywords: Furosemide, polyvinylpyrrolidone, glass solution, solid dispersion, amorphous, oral bioavailability 


\section{Introduction}

Furosemide, a loop diuretic, is widely used orally for treatment of hypertension and oedema (Goud et al., 2011; Matsuda et al., 1990). Furosemide is classified as class IV in the Biopharmaceutics Classification System (BCS), hence it has a low aqueous solubility in the physiological pH range $(5-20 \mu \mathrm{g} / \mathrm{ml})$ and at the same time, a poor intestinal permeability. The compound has weak acidic properties, two pKa values of 9.9 and 3.5 and is reported to be able to exist in seven different solid state forms: four polymorphs (I, II, III, IV), two solvates (IV-DMS and V-dioxane) and one amorphous form (Goud et al., 2011; Granero et al., 2010; Matsuda et al., 1990). The poor solubility of furosemide together with a tendency to undergo site-specific absorption in the stomach and upper small intestine, leads to a highly variable bioavailability of orallyadministered furosemide in humans (20-60\%) (lannuccelli et al., 2000).

To decrease variability and increase the overall oral bioavailability, it can be a useful strategy to improve the solubility and dissolution rate by converting the crystalline drug to its amorphous forms (Hancock and Zograf, 1997). The amorphous form of a drug lacks the three-dimensional long range order of molecular packing and is therefore, thermodynamically in a higher energetic state compared to its crystalline counterpart. This leads to a higher solubility and faster dissolution rate, but it also results in physical instability of the drug with a tendency to convert to a lower energy state (metastable or stable crystalline form) over time (storage and/or during dissolution) (Bates et al., 2006; Bikiaris, 2011; Hancock and Zograf, 1997). For furosemide, it was found that by utilising spray drying, an amorphous sodium salt of furosemide (ASSF) can be created (Nielsen et al., 2013a). ASSF exhibited a higher solubility at pH 6.5 together with 20 and 8-fold faster dissolution rate, when compared to the crystalline and amorphous acid forms of furosemide, respectively (Nielsen et al., 2013a). Moreover, the stability of ASSF during storage was found to be significantly longer compared to the amorphous acid form (Nielsen et al., 2013a). However, despite showing very promising in vitro properties, there was no significant difference in the oral bioavailability when ASSF was dosed orally to rats compared to the crystalline and amorphous acid forms of furosemide. Although ASSF led to a faster time to peak concentration ( $\left.T_{\max }\right)$, most likely related to the fast dissolution rate of the drug when compared to the two acid forms of furosemide (Nielsen et al., 2013a). The similar oral bioavailability of the three forms of furosemide may be explained by the conversion of ASSF to a trihydrate of furosemide during dissolution at pH 6.5 (Nielsen et al., 2013b).

In an attempt to stabilise undissolved ASSF during dissolution, solid dispersions have been investigated in the present study. The term solid dispersions has been defined as a dispersion of one or more active pharmaceutical ingredient (API) in an inert carrier or matrix. The formation of the solid dispersions (and more specifically glass solutions, i.e. single phase molecular dispersions of a drug in a polymer) has become one of the preferred methods to enhance drug dissolution and to stabilise the amorphous form of a drug (Chiou and Riegelman, 1971; Laitinen et al., 2013). The drug is dispersed in a polymer on a molecular level and a single homogeneous amorphous solid is formed, in many cases aided by drug-polymer intermolecular interactions (e.g. the formation of hydrogen bonds between the drug and polymer) (Patterson et al., 2005; Vasconcelos et al., 2007). The capability of the polymer to inhibit crystallisation of the amorphous form has been reported to be possible also at low polymer concentrations (Van den Mooter et al., 2001), and nucleation and crystal growth of the amorphous drug is inhibited by the intermolecular interactions. The ability of polymers to inhibit crystallisation of the amorphous drug can be linked to the increase in the glass transition temperature $\left(\mathrm{T}_{\mathrm{g}}\right)$ of the glass solution compared to that of the pure amorphous drug, leading to a decrease in drug mobility (Hancock and Zograf, 1997; Newman et al., 2011; Van den Mooter et al., 2001). 
Solid dispersions of furosemide at various concentrations of hydroxypropylmethylcellulose (HPMC) were previously studied to investigate if HPMC was able to stabilise ASSF during dissolution (Nielsen et al., 2013c). It was found that $80 \mathrm{w} / \mathrm{w} \%$ HPMC was necessary to stabilise ASSF during dissolution as solid dispersions containing 20 and $50 \mathrm{w} / \mathrm{w} \%$ HPMC resulted in conversion of ASSF to a more stable crystalline form within $1 \mathrm{~min}$ of dissolution at pH 6.5 (Nielsen et al., 2013c).

Besides cellulose based polymers, such as HPMC, poly(vinyl pyrrolidone) (PVP) is also widely utilised to prepare solid dispersions (and especially glass solution) (Alves et al., 2014; Newman et al., 2011). PVP is a hydrophilic polymer and is known to inhibit crystal growth and phase transformation (Akbuga et al., 1988; Paudel et al., 2013). Every drug will have different affinity to different polymers, and PVP has shown to have a strong hydrogen bonding capacity for example to felodipine (Konno and Taylor, 2006), but is also reported to be a useful component in solid dispersions with furosemide (Doherty and York, 1987). Furthermore, it is reported in the literature that the chain length of PVP significantly influences the dissolution rate of furosemide with PVP K30 providing the fastest dissolution rate compared to other PVP types (Akbuga et al., 1988). PVP K30 has also been shown to increase the physical stability of amorphous efavirenz (Alves et al., 2014), and it was also reported that solid dispersions with celecoxib and PVP K30 led to increased dissolution rate (Homayouni et al., 2014) and in addition a higher oral bioavailability compared to the pure drug (Ha et al., 2014).

The purpose of this study was to investigate if the stability during storage and dissolution of ASSF was improved when producing a glass solution of ASSF and PVP. Furthermore, it was studied if the oral in vivo performance of ASSF was enhanced in rats by use of the glass solution.

\section{Materials and methods}

\subsection{Materials}

Furosemide ( $>98 \%$ purity) and taurocholic acid sodium salt hydrate (sodium taurocholate) were acquired from Sigma-Aldrich (St. Louis, MO, USA). Polyvinylpyrrolidone (PVP K30) was obtained from Unikem (Copenhagen, Denmark), and phosphatidylcholine (Lipoid S PC, purity $\geq 98 \%$ ) was purchased from Lipoid AG (Ludwigshafen, Germany). Sodium azide and potassium dihydrogen phosphate were obtained from Merck (Darmstadt, Germany). Ultra-purified water was obtained from an SG Ultra Clear water system (SG Water USA, LLC, Nashua, NH, USA) and was freshly produced in all cases. All other chemicals employed were of analytical grade.

\subsection{Preparation and manufacturing of the glass solution containing furosemide and PVP}

In order to formulate the glass solution containing furosemide and PVP (80:20 w/w\%), the two compounds were mixed and dissolved in purified water at $\mathrm{pH} 10$ (adjusted with $\mathrm{NaOH}$ ). The solution was stirred overnight and spray dried the following day on a Büchi Mini Spray-Dryer B-290 (Büchi Labortechnik AG, Flawil, Switzerland) in a similar set-up as described previously (Nielsen et al., 2013c). A 0.7-mm nozzle was utilised for the spray drying process with air as the drying medium. Relevant spray drying parameters are listed in Table 1. Following completion of the process, the product was collected and stored in a glass vial protected from light.

Table 1: Process parameters for spray drying of the furosemide and PVP glass solution

\begin{tabular}{|l|l|}
\hline Process parameters & Furosemide and PVP glass solution \\
\hline Inlet temperature $\left({ }^{\circ} \mathrm{C}\right)$ & $185 \pm 5$ \\
\hline
\end{tabular}




\begin{tabular}{|l|l|}
\hline Outlet temperature $\left({ }^{\circ} \mathrm{C}\right)$ & $78 \pm 3$ \\
\hline Aspirator rate $(\%)$ & 80 \\
\hline Drying flow rate $\left(\mathrm{m}^{3} / \mathrm{h}\right)$ & 32 \\
\hline Pump flow rate $(\mathrm{mL} / \mathrm{min})$ & 3.6 \\
\hline
\end{tabular}

\subsection{Characterisation of furosemide in the glass solution by X-ray powder diffraction (XRPD)}

Following the spray drying process, XRPD was performed to determine the solid state form of furosemide in the formulation. Moreover, XRPD was used to confirm the solid state form after storage and dissolution. XRPD analyses were performed using an X'Pert PRO X-ray diffractometer (PANalytical, Almelo, The Netherlands; MPD PW3040/60 XRD; Cu KR anode; $\lambda=1.541 \AA ; 45 \mathrm{kV} ; 40 \mathrm{~mA}$ ). A starting angle of $5^{\circ} 2 \theta$ and an end angle of $35^{\circ} 2 \theta$ were utilised for the scans with a scan speed of $0.6565^{\circ} 2 \theta / \mathrm{min}$ and a step size of $0.01313^{\circ} 2 \theta$. Data were collected using $X^{\prime}$ Pert Data Collector software (PANalytical B.V.)

\subsection{Measurement of glass transition temperature $\left(T_{g}\right)$ by differential scanning calorimetry (DSC)}

DSC experiments were performed using a Discovery DSC 1-0216 (TA instruments, New Castle, DE, USA), operated with TRIOS software (version 3.0.1.3156). The glass solution (4-5 mg) was weighed into aluminium pans and sealed with pin-holed lids. A heating rate of $10 \mathrm{~K} / \mathrm{min}$ was employed, measuring from $10-200^{\circ} \mathrm{C}$ at a nitrogen flow rate of $20 \mathrm{~mL} / \mathrm{min}$.

\subsection{Biorelevant intestinal dissolution medium}

Release of ASSF from the formulation was investigated in simulated intestinal medium, pH 6.5. The medium contained $10 \mathrm{mM}$ of sodium taurocholate as the bile salt and $2.5 \mathrm{mM}$ of phosphatidylcholine as the phospholipid and was prepared as previously described (Nielsen et al., 2013a, 2013b).

\subsection{Biorelevant dissolution and intrinsic dissolution rate (IDR) of ASSF from the glass solution}

Release and dissolution of ASSF from the glass solution was investigated on a $\mu$ DISS profiler ( $p$ ION INC, Woburn, MA), with simulated intestinal medium as the release medium. Dissolution experiments were performed at $37 \pm 0.5^{\circ} \mathrm{C}$ using a stirring rate of $100 \pm 3 \mathrm{rpm} .1 \mathrm{~mm}$ path length in situ UV probes were employed on a $\mu$ DISS profiler. Each channel was calibrated with its own standard curve prior to experiments. For the calibration curves, aliquots of furosemide in water stock solution were repeatedly added to $10 \mathrm{~mL}$ of the simulated medium in order to achieve a range of defined standard concentrations, and the UV spectrum of each standard was recorded. The release experiments were performed both from powder (to obtain total release) and from compacts (for calculation of the intrinsic dissolution rate (IDR)). Accurately weighed 8-10 mg of the glass solutions was used for both sets of experiments. For the compact experiments miniaturized pellets of the glass solutions were then prepared using a Mini-IDR compression system (Heath Scientific, UK), and the pellet was compressed in the stainless steel die at 80 bar for $40 \mathrm{~s}$ to produce a uniform flat surface. The sample dies were placed into cylindrical magnetic stirring bars, and covered with $10 \mathrm{~mL}$ of release medium. For the powder experiments, the weighted powder was added to sample vials and covered with $10 \mathrm{~mL}$ of release medium. The release for both sets of experiments was measured by recording of UV spectra in individual channels for a total period of $180 \mathrm{~min}$. Dissolved furosemide concentrations were then determined by analysing recorded spectra at a wavelength range of 310-350 nm, with reference to the created calibration curves. PVP did not give any UV signal in this range. Release profiles of the glass solutions were collected in three replicates. 
For calculation of release and IDR of ASSF in the glass solution, the coefficient of determination $\left(R^{2}\right)$ from linear regression analysis was used to assess the quality of the fit of standard curves (described above) for IDR measurements. From the $\mu \mathrm{DISS}$ software, release curves with the concentration of released furosemide as a function of time were determined. The initial linear slope from the release curves was then used to calculate IDR, by employing the Noyes-Whitney equation (Avdeef and Tsinman, 2008; Noyes and Whitney, 1897).

\subsection{Stability investigations during storage and dissolution of ASSF in the glass solution by XRPD}

The physical stability of ASSF in the glass solution was studied by storing the formulation at $20 \pm 3^{\circ} \mathrm{C}$ and $0 \%$ relative humidity $(\mathrm{RH})$. The ASSF in the glass solution was regularly inspected for its solid state form using XRPD (settings are described in section 2.3) for up to 168 days.

For investigation of the solid state form of furosemide in the glass solutions during release, $\mu$ DISS experiments were also performed from compacts (as detailed in section 2.6) for shorter time periods of 1 , $3,5,10,20$, and $30 \mathrm{~min}$. Prior to and following experiments, drug compacts were analysed by XRPD (see section 2.3).

\subsection{Oral in vivo study in rats of the glass solution and of pure ASSF}

All animal care and experimental studies were approved by the Animal Welfare Committee, appointed by the Danish Ministry of Justice, and were carried out in compliance with EC Directive 2010/63/EU, the Danish law regulating experiments on animals and NIH Guidelines for the Care and Use of Laboratory Animals. The experiments were performed under the following license: 2012-15-2934-00186. The experimental animal work was performed at the Department of Experimental Medicine, University of Copenhagen, Denmark, which is accredited by the Association of Assessment and Accreditation of Laboratory Animal Care (AAALAC).

Male Sprague-Dawley rats (314-342 g on the experimental day) were purchased from Taconic (Bomholt, Denmark). Animals were acclimatised for a minimum of 7 days in groups of two on wooden bedding (Tapvei, Kortteinen, Finland) in plastic cages on standard feed (Altromin 1324, Altromin Spezialfutter, Lage, Germany) and carrots, with free access to fresh tap water in an air-conditioned building with controlled environmental parameters (humidity $40-60 \%$, temperature $20 \pm 1^{\circ} \mathrm{C}$, light from $6 a \mathrm{~m}-6 \mathrm{pm}$ ). Before entry into the experiments, the animals were fasted for approximately 6 hours and randomly assigned to receive one of the treatments. During the experiments, water was freely available.

The glass solution and the pure ASSF (both prepared one day prior to the experiment) were administered orally to the rats in gelatine capsules, size 9 (Torpac, NJ, USA). One day prior to the in vivo experiment, the capsules were filled with $4.5 \mathrm{mg}$ of ASSF (corresponding to $5.4 \mathrm{mg}$ of the glass solution) per capsule (equal to approximately $15 \mathrm{mg} / \mathrm{kg}$ dosed to the rats), by placing the bottom of the capsule in a stand and filling via a funnel. The capsules (one capsule per rat) were dosed with a dosing syringe (Torpac, NJ, USA) to the bottom of the oesophagus of the rat. Blood samples $(0.2 \mathrm{~mL})$ were taken from the tail vein by individual venipuncture and collected into EDTA coated tubes. Samples were collected at 10, 20, 30, 45 min, and 1, 2, $3,5,7$, and $24 \mathrm{~h}$ after drug administration Plasma was harvested immediately by centrifugation at 13,200 $\mathrm{rpm}(12 \mathrm{~min})$ and stored at $-20^{\circ} \mathrm{C}$ until further analysis.

The in vivo studies were performed in 5 and 6 replicated for the pure ASSF and the glass solution, respectively. 


\subsection{Quantitative analysis of plasma samples by liquid chromatography-mass spectrometry (LC-MS)}

Plasma samples were processed using $30 \mu \mathrm{l}$ of the plasma spiked with $300 \mu \mathrm{l}$ of acetonitrile to precipitate the proteins. The mixtures were centrifuged at $15,000 \mathrm{rpm}$ for $15 \mathrm{~min}$ at room temperature (Heraeus Sepatech Biofuge 15). After centrifugation the produced supernatants were transferred to HPLC vials and analysed by LC-MS. The LC-MS method was performed using an Agilent technologies 1200 system with a 6140 Quadrupole detector. Chromatographic separations were performed on a Phenomenex ${ }^{\circledR}$ Kintex C18 column $(4.6 \times 100 \mathrm{~mm}, 5 \mu \mathrm{m})$. The samples were eluted with a flow rate of $0.7 \mathrm{~mL} / \mathrm{min}$ in a gradient mixture of $0.04 \%$ acetic acid in purified water (solvent $A$ ) and acetonitrile (solvent $B$ ). The gradient program was as follows: $0-2 \mathrm{~min}, 25 \%$ solvent B; $2-3 \mathrm{~min}$, from 25 to $80 \%$ solvent B; $3-6 \mathrm{~min}, 80 \%$ solvent B; $6-7$ min, from 80 to $25 \%$ solvent $B ; 7-10 \mathrm{~min}, 25 \%$ solvent $B$. The autosampler temperature was kept at $5^{\circ} \mathrm{C}$ and injection volume of the sample was set at $5 \mu$ l. The LC-MS method was carried out using nitrogen to assist nebulisation. The electrospray ionization source was run in negative ion mode. The operational parameters of the ESI source were as follows: vaporiser temperature: $200^{\circ} \mathrm{C}$, gas temperature: $350^{\circ} \mathrm{C}$, drying gas flow: $12 \mathrm{~L} / \mathrm{min}$. A capillary potential of $2000 \mathrm{~V}$ was employed, and the fragmentor voltage was set to $110 \mathrm{~V}$ for detector pseudo-molecular ions $(328.90 \mathrm{~m} / \mathrm{z}$ and $329 \mathrm{~m} / \mathrm{z})$.

\subsection{Pharmacokinetic analyses}

The pharmacokinetic parameters following oral administration of furosemide were obtained by noncompartmental analysis. The area under the curve (AUC) of the plasma concentration versus time curves was determined by the linear log trapezoidal method from time $t=0$ min either to $t=180$ min or to the last plasma concentration measured at $t=1440 \mathrm{~min}$ after dosing. AUC values were used to calculate the relative bioavailability. The maximum furosemide plasma concentration $\left(C_{\max }\right)$ and time to peak concentration $\left(T_{\max }\right)$ were determined from the individual plasma concentration versus time curves.

\subsection{Statistical analysis}

In all cases of the in vitro data, results are expressed as mean \pm standard deviation (SD). The in vivo data are stated as mean \pm standard error of mean (SEM). Where appropriate, statistical analysis was carried out using student t-tests. Statistical analyses were carried out using GraphPad Prism version 6.05. P-values below $5 \%(p<0.05)$ were considered statistically significant.

\section{Results and discussion}

\subsection{Glass transition temperature $\left(T_{g}\right)$ of the glass solution}

To investigate if it was possible to stabilise ASSF with polymer especially during dissolution, spray drying was utilised as the method for preparing the glass solution. Spray drying is a well-established method when preparing glass solutions, and has the advantage of being a one-step process where the fast solvent evaporation results in an amorphous form of the drug within the formed glass solution (Bikiaris, 2011; Grohganz et al., 2014).

An essential parameter for characterising the amorphous form of a drug within the glass solution is the $T_{g}$ (here measured by DSC). With respect to amorphous forms in general, a high $\mathrm{T}_{\mathrm{g}}$ is a good indicator of an increased stability, as it suggests a reduced capability of crystallisation due to a lower molecular mobility (Guerrieri et al., 2010). The DSC measurement showed a $\mathrm{T}_{\mathrm{g}}$ of the glass solution of $121.3 \pm 0.5^{\circ} \mathrm{C}$ and PVP had a $\mathrm{T}_{\mathrm{g}}$ of $160.5 \pm 0.4^{\circ} \mathrm{C}$. It has previously been found that the $\mathrm{T}_{\mathrm{g}}$ for ASSF is $101.2^{\circ} \mathrm{C}$, hence, there should be a 
greater stability of ASSF in the glass solution compared to the pure ASSF. The DSC data also showed only a single $T_{g}$ as the only thermal event, indicating molecular miscibility of furosemide and PVP.

\subsection{Biorelevant dissolution of ASSF in the glass solution}

When developing a glass solution, it is important that the polymer does not have a negative effect on the dissolution and dissolution rate of the drug compared to the drug itself. To investigate the dissolution of ASSF in the glass solution, a physiologically relevant dissolution medium was employed to simulate the in vivo situation as closely as possible. In Figure $1 \mathrm{~A}$ it can be observed that the powder dissolution of ASSF in the glass solution in the simulated medium at pH 6.5 was very fast and after $1 \mathrm{~min}, 82.2 \pm 5.4 \%$ of furosemide was dissolved. The dissolution (from powder samples) was measured over a period of $180 \mathrm{~min}$ (corresponding to the in vivo transit time in the small intestine), and at the end of dissolution $85.6 \pm 3.0 \%$ of furosemide was released and dissolved from the glass solution (Figure 1A). To calculate the IDR of furosemide from the glass solution, discs of the glass solution were compressed and the dissolution was measured again. The IDR was found to be $10.1 \pm 0.6 \mathrm{mg} / \mathrm{cm}^{2} / \mathrm{min}$. In a previous study, the IDR for ASSF was $8.8 \pm 0.6 \mathrm{mg} / \mathrm{cm}^{2} / \mathrm{min}$ (Figure 1B) (Nielsen et al., 2013a), and significant difference was therefore found ( $p$ value 0.0236 ). It can therefore be concluded that PVP did affect the dissolution rate of ASSF in a positive fashion due to the hydrophilic nature of PVP (Halake et al., 2014). A fast dissolution rate is important for developing a good drug formulation of furosemide, and glass solutions will often provide this because of the hydrophilic properties of the polymer. When the glass solution is dispersed in water, the carrier will generally either dissolve or absorb water very fast facilitating release and dissolution of the drug (Vo et al., 2013).

A)

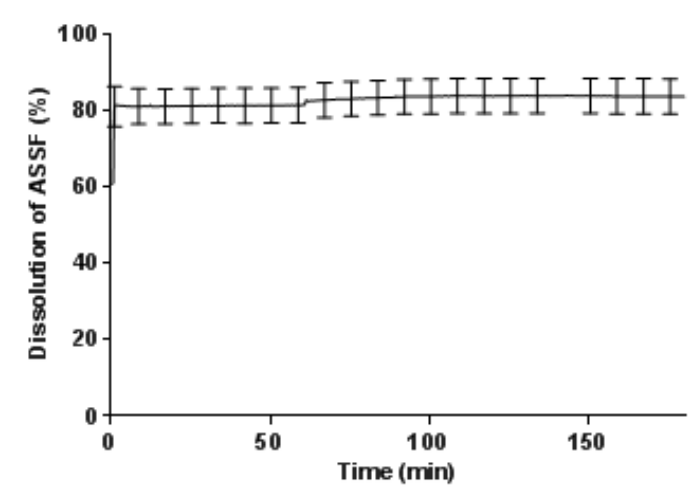

B)

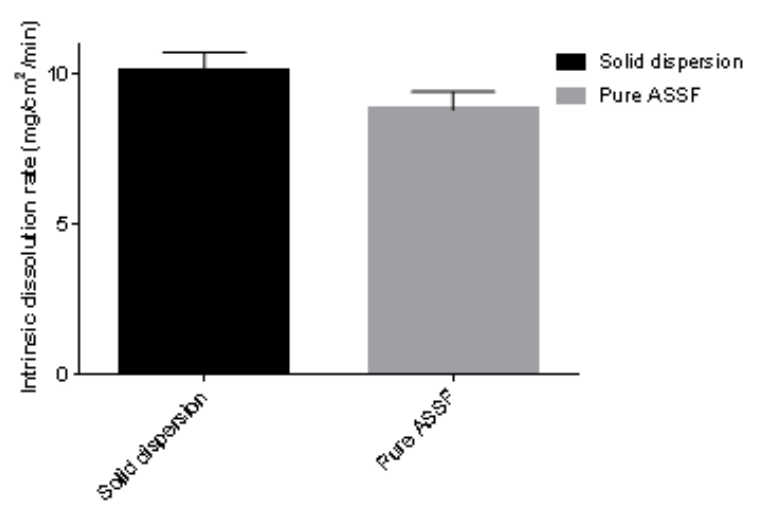

Figure 1: A) Dissolution profile of amorphous sodium salt of furosemide (ASSF) from the glass solution. B) Intrinsic dissolution rates (IDR) for ASSF in the glass solution and pure ASSF (Nielsen et al., 2013a), calculated from the initial slope (1-10 min) of the dissolution curve from disc dissolution. Both experiments were performed in simulated medium at $\mathrm{pH}$ 6.5. Data represent the mean \pm SD of 3 replicates. 


\subsection{Stability of ASSF in the glass solution during storage and dissolution}

In general, amorphous forms of drugs have a tendency to convert to a more stable crystalline form during storage and/or dissolution (Hancock and Zograf, 1997), and therefore it is a key point to investigate the stability of the amorphous drug in the glass solution.

The glass solution immediately after spray drying was shown by XRPD to contain the drug in an amorphous form (Figure 2). The glass solution was stored at $20^{\circ} \mathrm{C}$ and $0 \% \mathrm{RH}$ to investigate the stability of ASSF during storage, and from the characteristic halo pattern of the diffractogram in Figure 2, the continued presence of ASSF through the whole storage period (168 days) of the glass solution could be confirmed. It is well known from the literature that the relative crystallisation tendency of the amorphous drug in the glass solution is dependent of the pure drug form (Marsac et al., 2006). Earlier, ASSF has been shown to be stable at $22^{\circ} \mathrm{C}$ and $33 \% \mathrm{RH}$ for up to 291 days (Nielsen et al., 2013a), hence, it was expected that ASSF in the glass solution would still be on its amorphous form after 168 days. There is a good correlation with results from the literature. Here it has been reported when storing a glass solution of amorphous furosemide acid and PVP at temperatures varying from $6-45^{\circ} \mathrm{C}$ and $40 \% \mathrm{RH}$, no evidence of crystalline furosemide was observed over a period of 12 months, based on XRPD measurements (Doherty and York, 1989). Furthermore, a rule of thumb is that crystallisation can often be avoided if the amorphous drug is stored at temperatures $50^{\circ} \mathrm{C}$ or more below $\mathrm{T}_{\mathrm{g}}$ of the dispersion. At those temperatures, the molecular mobility of the drug is very low and therefore, the physical stability is high at these temperatures (Newman et al., 2011).

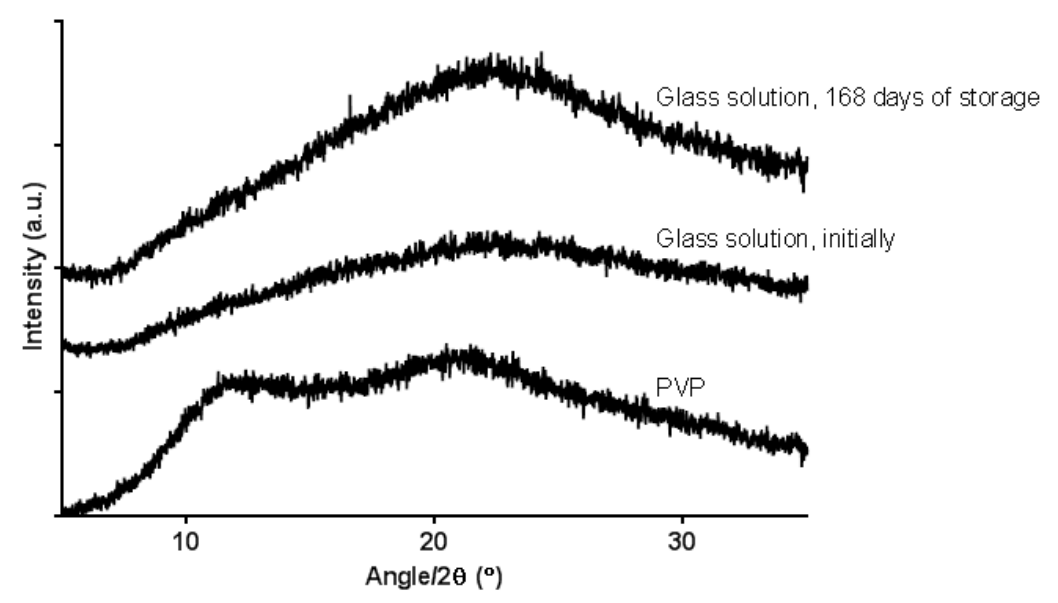

Figure 2: XRPD diffractograms of the glass solution of amorphous sodium salt of furosemide (ASSF) and PVP initially after spray drying and after 168 days of storage at $20^{\circ} \mathrm{C}$ and $0 \% \mathrm{RH}$. As reference the diffractogram of PVP is also shown.

The glass solution used in this study seemed stable during storage, but devitrification is often observed during dissolution (Kanaujia et al., 2011; Savolainen et al., 2009). In previous studies, it has been problematic to keep the ASSF in its amorphous form during dissolution at pH 6.5 (Nielsen et al., 2013b, 2013c), and therefore, it is essential to investigate the solid state form of furosemide in the glass solution also during dissolution. To investigate this, a dissolution experiment on a $\mu D I S S$ profiler in a simulated intestinal medium at pH 6.5 was performed together with off-line XRPD. The compact containing the glass solution was investigated on XRPD and already after 1 min of dissolution a small peak was observed in the otherwise halo pattern diffractogram (Figure 3). This is an indicator towards that the ASSF in the glass solution already converting to a crystalline form after $1 \mathrm{~min}$ of dissolution, and in Figure 3 it can be 
observed that the peaks grow during the $30 \mathrm{~min}$ of dissolution. Although, the ASSF in the glass solution seems to be partly crystalline during dissolution, this is occurring to a lesser extent compared to the pure ASSF.

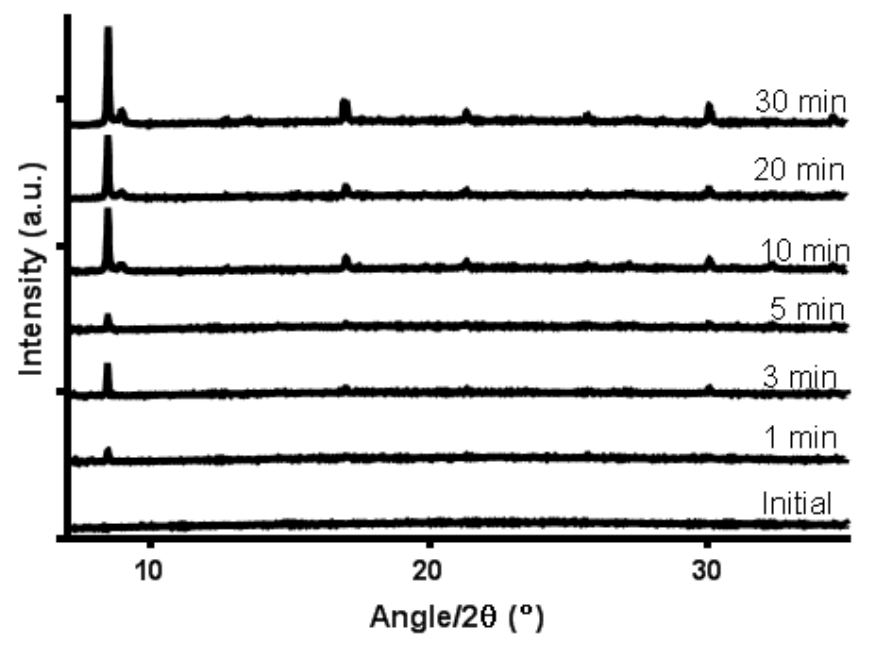

Figure 3: XRPD of amorphous sodium salt of furosemide (ASSF) in glass solution following 1, 3, 5, 10, 20, and $30 \mathrm{~min}$ of dissolution on a $\mu \mathrm{DISS}$ profiler in a simulated intestinal medium $\mathrm{pH}$ 6.5. Diffractogram of ASSF in the glass solution before dissolution is shown for reference.

In a previous study, the devitrification tendency of pure ASSF was tested in a similar set-up to here, and in this study ASSF was also found to crystallise after $1 \mathrm{~min}$ of dissolution (Nielsen et al., 2013b). For comparison, it can be observed that the ASSF in the glass solution crystallise slower than the pure ASSF by comparing the peaks at $1 \mathrm{~min}$ of dissolution in the diffractograms (taking into account that the ASSF in the glass solution contains $20 \%$ less ASSF) (Figure 4). After $30 \mathrm{~min}$ of dissolution, there are peaks corresponding to a crystalline form of furosemide in both the glass solution and for the pure ASSF, but for the pure ASSF the peak intensity appears to be slightly higher and several more peaks appear than for the ASSF in the glass solution (Figure 4). In the literature, it is found that pure ASSF crystallised to a trihydrate of furosemide when in contact with aqueous medium (Nielsen et al., 2013b). We have not specifically investigated to what polymorph the furosemide in the glass solution converted during dissolution but from Figure 4 it can be concluded that the drug in the glass solution does not crystallise to its crystalline acid form. This means that PVP in the glass solution has a stabilising effect on ASSF and PVP by its characteristic of being a crystallisation inhibitor decreases the crystallinity of ASSF in the glass solution. It is found in the literature that PVP has previously been able to stabilise amorphous furosemide acid, and it was found that 1:3 and 1:5 ratios of drug to polymer were the best choice to stabilise the amorphous furosemide acid (lannuccelli et al., 2000). In the current study, the ratio (4:1) is much below that, indicating that PVP even in small amounts can stabilise the ASSF both during storage and dissolution. 


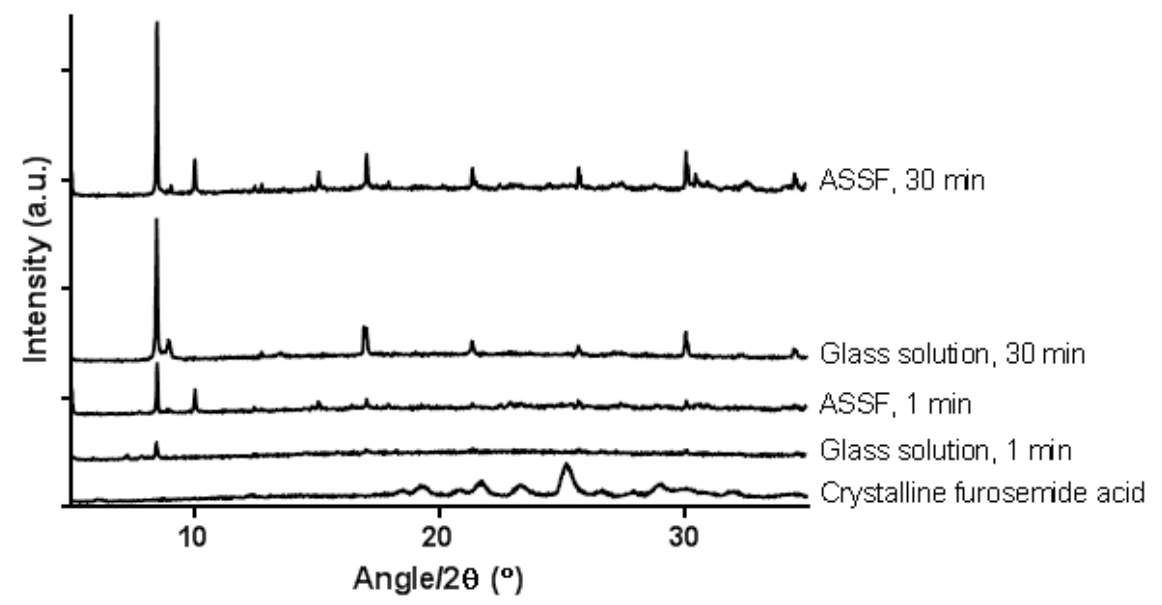

Figure 4: XRPD of amorphous sodium salt of furosemide (ASSF) in glass solution at 1 and 30 min as found in Figure 2 and the XRPD diffractograms for pure ASSF after 1 and $30 \mathrm{~min}$ of dissolution in a simulated intestinal medium at pH 6.5 (Nielsen et al., 2013b). As reference the diffractogram of crystalline furosemide acid has been added.

\subsection{Oral in vivo study in rats of the glass solution and of pure ASSF}

As the in vitro studies showed that PVP decreased the crystallinity of ASSF in the glass solution compared to the pure ASSF at $\mathrm{pH} \mathrm{6.5,} \mathrm{an} \mathrm{in} \mathrm{vivo} \mathrm{pharmacokinetic} \mathrm{study} \mathrm{was} \mathrm{performed} \mathrm{in} \mathrm{rats,} \mathrm{in} \mathrm{order} \mathrm{to} \mathrm{assess} \mathrm{if} \mathrm{this}$ was also translated to the in vivo situation. In the literature, it is reported that a glass solution will not influence on the permeability properties of a drug (Miller et al., 2012), and therefore it is believed that the in vivo data can be interpreted based on the dissolution data. Figure 5 shows the mean plasma concentration versus time profiles for the two ASSF formulations, and the noncompartmental pharmacokinetic parameters are provided in Table 2. The oral dosing of the ASSF formulations resulted in no significant difference ( $p$-value 0.7447 ) in the $T_{\max }$ value. Even though IDR values are expected to be closely related to the in vivo drug dissolution dynamics (Yu et al., 2004), the difference in the IDR values in the in vitro studies of the ASSF in the glass solution compared to pure ASSF, did not reflect in a significant difference in the $T_{\max }$ values. In terms of the $C_{\max }$ and $A \cup C_{0-180 \text { min, }}$ no significant difference was observed between the two formulations ( $p$-value 0.5438 and $p$-value 0.3939 , respectively). However, a greater $A \cup C_{0}$ $1440 \mathrm{~min}$ was found for ASSF in the glass solution, compared to pure ASSF ( $p$-value 0.0449). Figure 5 reveals that the difference in AUC starts to set in after approximately $120 \mathrm{~min}$ and continues until the end of the experiment (1440 $\mathrm{min})$. The higher AUC for the glass solution also led to a higher relative bioavailability of the ASSF in the glass solution compared to pure ASSF of $262.7 \%$. Assuming that the absorption kinetics for ASSF in the glass solution and for pure ASSF are identical, the difference in the higher AUC for the ASSF in the glass solution can be explained by that the ASSF in the glass solution having a lower tendency to crystallise during dissolution compared to pure ASSF resulting in a longer absorption phase. In general, it is found that there is a good correlation between humans and rats in terms of oral absorption of drugs (Chiou et al., 2000), and therefore the ASSF and PVP glass solution could be a promising formulation for furosemide in terms of a higher bioavailability compared to the pure ASSF and crystalline furosemide acid (Nielsen et al., 2013a). 


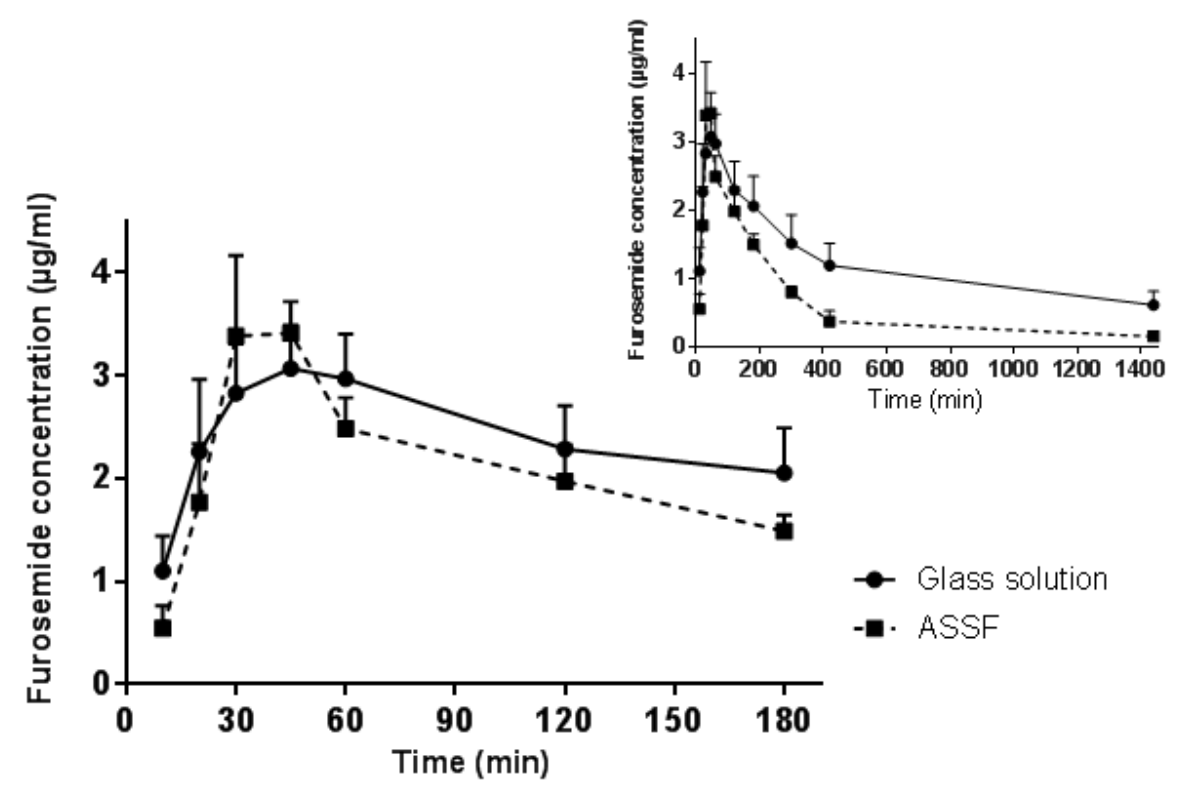

Figure 5: Plasma concentrations of the glass solution and pure amorphous sodium salt of furosemide (ASSF) dosed in gelatin capsules orally to rats. Data represent mean \pm SEM, with $n=5-6$.

Table 2: Noncompartmental pharmacokinetic parameters of the glass solution and pure amorphous sodium salt of furosemide (ASSF) following oral administration to rats. Data represent mean $\pm S D$, with $n=5-6$.

\begin{tabular}{|l|l|l|}
\hline & Glass solution & $\begin{array}{l}\text { Amorphous sodium salt } \\
\text { of furosemide (ASSF) }\end{array}$ \\
\hline $\mathbf{T}_{\max }(\mathrm{min})$ & $38.3 \pm 5.9$ & $36.0 \pm 3.7$ \\
\hline $\mathrm{C}_{\max }(\mu \mathrm{g} / \mathrm{mL})$ & $3.5 \pm 0.4$ & $3.9 \pm 0.6$ \\
\hline AUC $_{\mathbf{0}-180 \min }$ & $436.1 \pm 64.5$ & $373.0 \pm 24.6$ \\
\hline AUC $_{\mathbf{0}-1440 \min }$ & $2169.1 \pm 529.2$ & $736.3 \pm 61.1$ \\
\hline Relative bioavailability (\%) $^{\mathbf{1}}$ & $262.7 \pm 177.1$ & - \\
\hline
\end{tabular}

${ }^{1}$ Relative bioavailability was determined as: $100 x\left(A \cup C_{\text {glass solution }} /\right.$ dose $\left._{\text {glass solution }}\right) /\left(\mathrm{AUC}_{\mathrm{ASSF}} /\right.$ dose $\left._{\mathrm{ASSF}}\right)$

\section{Conclusion}

A glass solution of ASSF and PVP $(80: 20 \mathrm{w} / \mathrm{w} \%)$ has been prepared by spray drying. The $T_{\mathrm{g}}$ of the glass solution was found to be higher than the $T_{\mathrm{g}}$ for the pure ASSF, and in addition, IDR for the glass solution was found to be faster than for the pure ASSF. PVP was shown to be able to stabilise the amorphous form of furosemide during storage (for 168 days) and PVP decreased the crystallisation tendency of ASSF compared to pure ASSF during dissolution in a simulated medium at $\mathrm{pH}$ 6.5. This led to a relative oral bioavailability of the glass solution of $262.7 \%$ compared to ASSF when dosed orally to rats. These results show that the ASSF has potential as a drug formulation for oral delivery of furosemide and would possibly increase the oral bioavailability of furosemide in humans. 


\section{Acknowledgement}

The authors would like to acknowledge the Villum Kann Rasmussen Foundation and the Danish Research Council for Technology and Production (FTP), Project DFF - 4004-00120B for financial support. Moreover, the NAnoMEChanical sensors and actuators, fundamentals and new directions (NAMEC) - a VKR Centre of

Excellence is acknowledged. Furthermore, the personnel at the Department of Experimental Medicine University of Copenhagen, Denmark are acknowledged for their skilful handling of the rats. 


\section{Reference list}

Akbuga, J., Gursoy, A., Kendi, E., 1988. The Preparation and Stability of Fast Release Furosemide-Pvp Solid Dispersion. Drug Dev. Ind. Pharm. 14, 1439-1464. doi:10.3109/03639048809151942

Alves, L.D.S., De La Roca Soares, M.F., De Albuquerque, C.T., Da Silva, É.R., Vieira, A.C.C., Fontes, D.A.F., Figueirêdo, C.B.M., Soares Sobrinho, J.L., Rolim Neto, P.J., 2014. Solid dispersion of efavirenz in PVP K30 by conventional solvent and kneading methods. Carbohydr. Polym. 104, 166-174. doi:10.1016/j.carbpol.2014.01.027

Avdeef, A., Tsinman, O., 2008. Miniaturized rotating disk intrinsic dissolution rate measurement: Effects of buffer capacity in comparisons to traditional Wood's apparatus. Pharm. Res. 25, 2613-2627. doi:10.1007/s11095-008-9679-z

Bates, S., Zografi, G., Engers, D., Morris, K., Crowley, K., Newman, A., 2006. Analysis of amorphous and nanocrystalline solids from their X-ray diffraction patterns. Pharm. Res. 23, 2333-2349. doi:10.1007/s11095-006-9086-2

Bikiaris, D.N., 2011. Solid dispersions, Part I: recent evolutions and future opportunities in manufacturing methods for dissolution rate enhancement of poorly water-soluble drugs. Expert Opin. Drug Deliv. 8, 1501-1519. doi:10.1517/17425247.2011.618181

Chiou, P.W., Yu, B., Kuo, C.-Y., 2000. Comparison of Digestive Function Among Rabbits, Guinea-Pigs, Rats and Hamsters. I. Performance, Digestibility and Rate of Digesta Passage. Asian-Australasian J. Anim. Sci. 13.

Chiou, W.L., Riegelman, S., 1971. Pharmaceutical applications of solid dispersion systems. J. Pharm. Sci. 60, 1281-1302. doi:10.1002/jps.2600600902

Doherty, C., York, P., 1987. Mechanisms of Dissolution of Frusemide Pvp Solid Dispersions. Int. J. Pharm. 34, 197-205. doi:10.1016/0378-5173(87)90180-3

Doherty, C., York, P., 1989. Accelerated Stability of an X-Ray Amorphous Frusemide-Polyvinylpyrrolidone Solid Dispersion. Drug Dev. Ind. Pharm. 15, 1969-1987. doi:10.3109/03639048909052513

Goud, R., Swarupa, G., Suresh, K., Pal, S., Manjunatha, S.G., Nambiar, S., Nangia, A., 2011. Novel Furosemide Cocrystals and Selection of High Solubility Drug Forms. J. Pharm. Sci. 101, 664-680. doi:10.1002/jps

Granero, G.E., Longhi, M.R., Mora, M.J., Junginger, H.E., Midha, K.K., Shah, V.P., Stavchansky, S., Dressman, J.B., Barends, D.M., 2010. Biowaiver Monographs for Immediate Release Solid Oral Dosage Forms: Furosemide. J. Pharm. Sci. 99, 2544-2556. doi:10.1002/jps.22030

Grohganz, H., Priemel, P.A., Lobmann, K., Nielsen, L.H., Laitinen, R., Mullertz, A., Van den Mooter, G., Rades, T., 2014. Refining stability and dissolution rate of amorphous drug formulations. Expert Opin. Drug Deliv. 11, 977-989. doi:10.1517/17425247.2014.911728

Guerrieri, P., Rumondor, A.C.F., Li, T., Taylor, L.S., 2010. Analysis of relationships between solid-state properties, counterion, and developability of pharmaceutical salts. AAPS PharmSciTech 11, 1212-22. doi:10.1208/s12249-010-9499-4

Ha, E.-S., Choo, G.-H., Baek, I.-H., Kim, M.-S., 2014. Formulation, Characterization, and in Vivo Evaluation of Celecoxib-PVP Solid Dispersion Nanoparticles Using Supercritical Antisolvent Process. Molecules 19, 20325-20339. doi:10.3390/molecules191220325

Halake, K., Birajdar, M., Kim, B.S., Bae, H., Lee, C., Kim, Y.J., Kim, S., Kim, H.J., Ahn, S., An, S.Y., Lee, J., 2014. Recent application developments of water-soluble synthetic polymers. J. Ind. Eng. Chem. 20, 39133918. doi:10.1016/j.jiec.2014.01.006 
Hancock, B.C., Zograf, G., 1997. Characteristics and significance of the amorphous state in pharmaceutical systems. J. Pharm. Sci. 86, 1-12. doi:10.1021/js9601896

Homayouni, A., Sadeghi, F., Varshosaz, J., Garekani, H.A., Nokhodchi, A., 2014. Comparing various techniques to produce micro/nanoparticles for enhancing the dissolution of celecoxib containing PVP. Eur. J. Pharm. Biopharm. 88, 261-274. doi:10.1016/j.ejpb.2014.05.022

Iannuccelli, V., Coppi, G., Leo, E., Fontana, F., Bernabei, M.T., 2000. PVP solid dispersions for the controlled release of furosemide from a floating multiple-unit system. Drug Dev. Ind. Pharm. 26, 595-603. doi:10.1081/ddc-100101274

Kanaujia, P., Lau, G., Ng, W.K., Widjaja, E., Hanefeld, A., Fischbach, M., Maio, M., Tan, R.B.H., 2011. Nanoparticle Formation and Growth During In Vitro Dissolution of Ketoconazole Solid Dispersion. J. Pharm. Sci. 100, 2876-2885. doi:10.1002/jps.22491

Konno, H., Taylor, L.S., 2006. Influence of different polymers on the crystallization tendency of molecularly dispersed amorphous felodipine. J. Pharm. Sci. 95, 2692-2705. doi:10.1002/jps.20697

Laitinen, R., Lobmann, K., Strachan, C.J., Grohganz, H., Rades, T., 2013. Emerging trends in the stabilization of amorphous drugs. Int. J. Pharm. 453, 65-79. doi:10.1016/j.ijpharm.2012.04.066

Marsac, P.J., Konno, H., Taylor, L.S., 2006. A comparison of the physical stability of amorphous felodipine and nifedipine systems. Pharm. Res. 23, 2306-2316. doi:10.1007/s11095-006-9047-9

Matsuda, Y., Tatsumi, E., Thermal, S., 1990. Physicochemical characterization of furosemide modifications. Int. J. Pharmceutics 60, 11-26.

Miller, J.M., Beig, A., Carr, R.A., Spence, J.K., Dahan, A., 2012. A Win-Win Solution in Oral Delivery of Lipophilic Drugs: Supersaturation via Amorphous Solid Dispersions Increases Apparent Solubility without Sacrifice of Intestinal Membrane Permeability. Mol. Pharm. 9, 2009-2016. doi:10.1021/mp300104s

Newman, A., Knipp, G., Zografi, G., 2011. Assessing the performance of amorphous solid dispersions. J. Pharm. Sci. 101, 1355-1377. doi:10.1002/jps.23031

Nielsen, L.H., Gordon, S., Holm, R., Selen, A., Rades, T., Mullertz, A., 2013a. Preparation of an amorphous sodium furosemide salt improves solubility and dissolution rate and leads to a faster T-max after oral dosing to rats. Eur. J. Pharm. Biopharm. 85, 942-951. doi:10.1016/j.ejpb.2013.09.002

Nielsen, L.H., Gordon, S., Pajander, J.P., Ostergaard, J., Rades, T., Mullertz, A., 2013b. Biorelevant characterisation of amorphous furosemide salt exhibits conversion to a furosemide hydrate during dissolution. Int. J. Pharm. 457, 14-24. doi:10.1016/j.ijpharm.2013.08.029

Nielsen, L.H., Rades, T., Müllertz, A., 2013c. Characterization during storage and dissolution of Solid dispersions containing furosemide and hydroxypropyl methylcellulose. J. Drug Deliv. Sci. Technol. 23, 409-415.

Noyes, A.A., Whitney, W.R., 1897. The rate of solution of solid substances in their own solutions. J. Am. Chem. Soc. 19, 930-934.

Patterson, J.E., James, M.B., Forster, A.H., Lancaster, R.W., Butler, J.M., Rades, T., 2005. The influence of thermal and mechanical preparative techniques on the amorphous state of four poorly soluble compounds. J. Pharm. Sci. 94, 1998-2012. doi:10.1002/jps.20424

Paudel, A., Worku, Z.A., Guns, J.M.S., Guns, S., Van den Mooter, G., 2013. Manufacturing of solid dispersions of poorly water soluble drugs by spray drying: Formulation and process considerations. Int. J. Pharm. 453, 253-284. doi:10.1016/j.ijpharm.2012.07.015 
Savolainen, M., Kogermann, K., Heinz, a., Aaltonen, J., Peltonen, L., Strachan, C., Yliruusi, J., 2009. Better understanding of dissolution behaviour of amorphous drugs by in situ solid-state analysis using Raman spectroscopy. Eur. J. Pharm. Biopharm. 71, 71-79. doi:10.1016/j.ejpb.2008.06.001

Van den Mooter, G., Wuyts, M., Blaton, N., Busson, R., Grobet, P., Augustijns, P., Kinget, R., 2001. Physical stabilisation of amorphous ketoconazole in solid dispersions with polyvinylpyrrolidone K25. Eur. J. Pharm. Sci. 12, 261-269. doi:10.1016/s0928-0987(00)00173-1

Vasconcelos, T., Sarmento, B., Costa, P., 2007. Solid dispersions as strategy to improve oral bioavailability of poor water soluble drugs. Drug Discov. Today 12, 1068-1075. doi:10.1016/j.drudis.2007.09.005

Vo, C.L.N., Park, C., Lee, B.J., 2013. Current trends and future perspectives of solid dispersions containing poorly water-soluble drugs. Eur. J. Pharm. Biopharm. 85, 799-813. doi:10.1016/j.ejpb.2013.09.007

Yu, L.X., Carlin, A.S., Amidon, G.L., Hussain, A.S., 2004. Feasibility studies of utilizing disk intrinsic dissolution rate to classify drugs. Int. J. Pharm. 270, 221-227. doi:10.1016/j.ijpharm.2003.10.016 